\title{
Particulate matter air pollution components and incidence of cancers of the stomach and the upper aerodigestive tract in the European Study of Cohorts of Air Pollution Effects (ESCAPE) ${ }^{\text {is }}$
}

Gudrun Weinmayr $^{\mathrm{a}, *}$, Marie Pedersen ${ }^{\mathrm{b}, \mathrm{c}}$, Massimo Stafoggia ${ }^{\mathrm{d}, \mathrm{e}}$, Zorana J. Andersen ${ }^{\mathrm{b}}$, Claudia Galassi ${ }^{\mathrm{f}}$, Jule Munkenast ${ }^{\mathrm{a}}$, Andrea Jaensch ${ }^{\mathrm{a}}$, Bente Oftedal ${ }^{\mathrm{g}}$, Norun H. Krog ${ }^{\mathrm{g}}$, Geir Aamodt ${ }^{\mathrm{h}}$, Andrei Pyko ${ }^{\mathrm{e}}$, Göran Pershagen ${ }^{\mathrm{e}}$, Michal Korek ${ }^{\mathrm{e}}$, Ulf De Faire ${ }^{\mathrm{e}}$, Nancy L. Pedersen ${ }^{\mathrm{i}}$, Claes-Göran Östenson ${ }^{j}$, Debora Rizzuto ${ }^{k}$, Mette Sørensen ${ }^{c}$, Anne Tjønneland ${ }^{c}$, Bas Bueno-de-Mesquita ${ }^{1}$, Roel Vermeulen ${ }^{\mathrm{m}, \mathrm{n}, \mathrm{o}}$, Marloes Eeftens ${ }^{\mathrm{o}, \mathrm{p}, \mathrm{q}}$, Hans Concin ${ }^{\mathrm{r}}$, Alois Lang ${ }^{\mathrm{s}}$, Meng Wang ${ }^{\mathrm{t}}$, Ming-Yi Tsai ${ }^{\mathrm{p}, \mathrm{q}, \mathrm{t}}$, Fulvio Ricceri ${ }^{\mathrm{u}, \mathrm{v}}$, Carlotta Sacerdote ${ }^{\mathrm{f}}$, Andrea Ranzi ${ }^{\mathrm{w}}$, Giulia Cesaroni $^{\mathrm{d}}$, Francesco Forastiere ${ }^{\mathrm{d}}$, Kees de Hoogh $^{\mathrm{p}, \mathrm{q}}$, Rob Beelen ${ }^{\mathrm{o}, \mathrm{x}, 1}$, Paolo Vineis ${ }^{\mathrm{m}, \mathrm{y}}$, Ingeborg Kooter ${ }^{\mathrm{z}}$, Ranjeet Sokhi ${ }^{\mathrm{aa}}$, Bert Brunekreef ${ }^{\mathrm{lo}}$, Gerard Hoek ${ }^{\mathrm{o}}$, Ole Raaschou-Nielsen ${ }^{\mathrm{c}, \mathrm{ab}}$, Gabriele Nagel ${ }^{\mathrm{a}, \mathrm{r}}$

a Institute of Epidemiology and Medical Biometry, Ulm University, Ulm, Germany

${ }^{\mathrm{b}}$ Section of Environmental Health, Department of Public Health, University of Copenhagen, Copenhagen, Denmark

${ }^{\mathrm{c}}$ The Danish Cancer Society Research Center, Copenhagen, Denmark

d Department of Epidemiology, Lazio Regional Health Service, ASL Roma 1, Rome, Italy

e Institute of Environmental Medicine, Karolinska Institutet, Stockholm, Sweden

${ }^{\mathrm{f}}$ Unit of Cancer Epidemiology, Città della Salute e della Scienza University-Hospital and Center for Cancer Prevention (CPO), Turin, Italy

${ }^{\mathrm{g}}$ Norwegian Institute of Public Health, Oslo, Norway

h Department of Public Health Science, LANDSAM, NMBU, Ås, Norway

i Department of Medical Epidemiology and Biostatistics, Karolinska Institute, Stockholm, Sweden

${ }^{\mathbf{j}}$ Department of Molecular Medicine and Surgery, Karolinska Institute, Stockholm, Sweden

${ }^{\mathbf{k}}$ Aging Research Center, Department of Neurobiology Care Science and Society, Karolinska Institutet and Stockholm University, Stockholm, Sweden

${ }^{1}$ Department of Epidemiology and Biostatistics, School of Public Health, Imperial College, London, UK

$\mathrm{m}$ Julius Center for Health Sciences and Primary Care, University Medical Center Utrecht, the Netherlands

${ }^{\mathrm{n}}$ MRC-PHE Centre for Environment and Health, Department of Epidemiology and Biostatistics, School of Public Health, Imperial College, London, UK

${ }^{\circ}$ Institute for Risk Assessment Sciences, Utrecht University, Utrecht, the Netherlands

P Swiss Tropical and Public Health Institute, Basel, Switzerland; University of Basel, Basel, Switzerland

${ }^{\mathrm{q}}$ University of Basel, Basel, Switzerland

${ }^{\mathrm{r}}$ Agency for Preventive and Social Medicine, Bregenz (aks), Austria

${ }^{s}$ Vorarlberg cancer registry; Agency for Preventive and Social Medicine, Bregenz (aks), Austria

${ }^{\mathrm{t}}$ Department of Environmental and Occupational Health Sciences, University of Washington, Seattle, WA, USA

' Unit of Epidemiology, Regional Health Service ASL TO3, Grugliasco, Italy

${ }^{\vee}$ Department of Clinical and Biological Sciences, University of Turin, Orbassano, Italy

${ }^{\mathrm{w}}$ Environmental Health Reference Centre, Regional Agency for Environmental Prevention of Emilia-Romagna, Modena, Italy

${ }^{\mathrm{x}}$ National Institute for Public Health and the Environment (RIVM), Bilthoven, the Netherlands

${ }^{y}$ Molecular end Epidemiology Unit, HuGeF, Human Genetics Foundation, Torino, Italy

${ }^{\mathrm{z}}$ Netherlands Organization for Applied Scientific Research, Utrecht, the Netherlands

aa Centre for Atmospheric and Climate Physics Research (CACP), University of Hertfordshire, Hatfield, UK

${ }^{\mathrm{ab}}$ Department of Environmental Science, Aarhus University, Roskilde, Denmark

\footnotetext{
This work was supported by: the German Cancer Aid [111010] to GW and GN; the European Community's Seventh Framework Program (FP7/2007-2011)

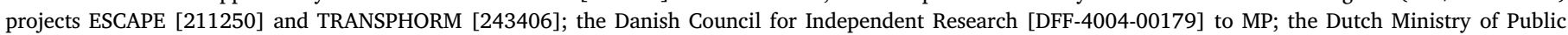

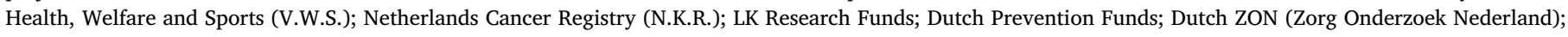
World Cancer Research Fund (WCRF); and Statistics Netherlands (The Netherlands); the Danish Cancer Society.

* Corresponding author at: Institute of Epidemiology and Medical Biometry, Ulm University, Helmholtzstr.22, 89081 Ulm, Germany.

E-mail address: gudrun.weinmayr@uni-ulm.de (G. Weinmayr).

${ }^{1}$ This paper is dedicated to Rob Beelen who was the coordinating PostDoc of ESCAPE and who died far too early in September 2017. He will live in our memories as a great scientist and precious colleague - and a wonderful person.
} 


\section{A R T I C L E I N F O}

Handling Editor: Xavier Querol

Keywords:

Gastric cancer

Upper aerodigestive tract cancer

Air pollution

Particulate matter components

Chemical elements

Sulphur

ESCAPE

\begin{abstract}
A B S T R A C T
Introduction: Previous analysis from the large European multicentre ESCAPE study showed an association of ambient particulate matter $<2.5 \mu \mathrm{m}\left(\mathrm{PM}_{2.5}\right)$ air pollution exposure at residence with the incidence of gastric cancer. It is unclear which components of PM are most relevant for gastric and also upper aerodigestive tract (UADT) cancer and some of them may not be strongly correlated with PM mass. We evaluated the association between long-term exposure to elemental components of $\mathrm{PM}_{25}$ and $\mathrm{PM}_{10}$ and gastric and UADT cancer incidence in European adults.

Methods: Baseline addresses of individuals were geocoded and exposure was assessed by land-use regression models for copper ( $\mathrm{Cu}$ ), iron ( $\mathrm{Fe}$ ) and zinc ( $\mathrm{Zn}$ ) representing non-tailpipe traffic emissions; sulphur (S) indicating long-range transport; nickel (Ni) and vanadium (V) for mixed oil-burning and industry; silicon (Si) for crustal material and potassium $(\mathrm{K})$ for biomass burning. Cox regression models with adjustment for potential confounders were used for cohort-specific analyses. Combined estimates were determined with random effects metaanalyses.

Results: Ten cohorts in six countries contributed data on 227,044 individuals with an average follow-up of 14.9 years with 633 incident cases of gastric cancer and 763 of UADT cancer.

The combined hazard ratio (HR) for an increase of $200 \mathrm{ng} / \mathrm{m}^{3}$ of $\mathrm{PM}_{2.5} \mathrm{~S}$ was 1.92 (95\%-confidence interval (95\%-CI) $1.13 ; 3.27)$ for gastric cancer, with no indication of heterogeneity between cohorts $\left(\mathrm{I}^{2}=0 \%\right)$, and 1.63 (95\%-CI 0.88;3.01) for $\mathrm{PM}_{2.5} \mathrm{Zn}\left(\mathrm{I}^{2}=70 \%\right)$. For the other elements in $\mathrm{PM}_{2.5}$ and all elements in $\mathrm{PM}_{10}$ including $\mathrm{PM}_{10} \mathrm{~S}$, non-significant HRs between 0.78 and 1.21 with mostly wide CIs were seen. No association was found between any of the elements and UADT cancer. The HR for $\mathrm{PM}_{2.5} \mathrm{~S}$ and gastric cancer was robust to adjustment for additional factors, including diet, and restriction to study participants with stable addresses over follow-up resulted in slightly higher effect estimates with a decrease in precision. In a two-pollutant model, the effect estimate for total $\mathrm{PM}_{2.5}$ decreased whereas that for $\mathrm{PM}_{2.5} \mathrm{~S}$ was robust.

Conclusion: This large multicentre cohort study shows a robust association between gastric cancer and long-term exposure to $\mathrm{PM}_{2.5} \mathrm{~S}$ but not $\mathrm{PM}_{10} \mathrm{~S}$, suggesting that $\mathrm{S}$ in $\mathrm{PM}_{2.5}$ or correlated air pollutants may contribute to the risk of gastric cancer.
\end{abstract}

\section{Introduction}

Long-term exposure to ambient air pollution with particles contributes to increased cancer risk (International Agency for Research on Cancer Monograph Working Group, 2015), with most evidence for lung cancer (Raaschou-Nielsen et al., 2013).

A previous analysis of the large European multicentre ESCAPE study showed an association of particulate matter $<2.5 \mu \mathrm{m}\left(\mathrm{PM}_{2.5}\right)$ exposure at residence with the incidence of gastric cancer (Nagel et al., 2018). For the incidence of upper aerodigestive tract (UADT) cancer, which summarises anatomically closely related sites, no association with $\mathrm{PM}_{2.5}$ or $\mathrm{PM}_{10}$ was found (Nagel et al., 2018).

PM constitutes a complex mixture depending on contributing sources and atmospheric processes, and it is still not clear which PM components are the most relevant for health, which may vary by endpoints. Although we did not find any association of PM mass with UADT cancer in our earlier work, it cannot be excluded that some components which may not be strongly correlated with PM mass may still have a role in carcinogenesis of UADT cancers.

The identification of elemental components of PM air pollution increasing cancer risk may increase our understanding of pathomechanisms and contribute to the identification of specific sources of relevance (Kelly and Fussell, 2012). Components of outdoor air pollutions for which adverse health effects have been reported include metals, inorganic components, secondary aerosols (sulphate, nitrate) and organic components (de Hoogh et al., 2013). The fact that these components do not occur in isolation, but in a temporally and spatially variable air pollution mix, renders epidemiological studies of individual components complex. While the focus has mostly been on traffic exhaust related components so far, recent reviews have pointed out the possible role of non-exhaust related particle components (Kelly and Fussell, 2015). For example, transition metals such as copper $(\mathrm{Cu})$ and iron (Fe) resulting from brake and tyre wear are likely to promote inflammation and oxidative stress (Hampel et al., 2015). While elements may have health effects per se, some of them also originate predominantly from certain sources (Viana et al., 2008) and may, as indicators for the related pollution mix, inform on effective preventions measures. To date, research on the influence of long-term exposure to different air-borne elements is scarce.

The objective of this study was therefore to investigate the association of chronic exposure to elemental components of PM air pollution with the incidence of gastric and UADT cancer. The study was performed in the framework of ESCAPE and the European study of Transport-related Air Pollution and Health Impacts-Integrated Methodologies for Assessing Particulate Matter (TRANSPHORM; www. transphorm.eu/).

\section{Material and methods}

Study population, outcome, confounder data and statistical analysis were identical to the previous analysis of air pollution and gastric/ UADT cancer (Nagel et al., 2018).

\subsection{Study population}

For the present study, prospective cohort data from seven study areas (Fig. 1) that had participated in ESCAPE (Raaschou-Nielsen et al., 2013) and had data on PM elemental composition and the resources to perform these additional analyses were analysed: Sweden ([CEANS] comprising the Swedish National Study on Aging and Care in Kungsholmen [SNAC-K], Stockholm Screening Across the Lifespan Twin study and TwinGene [SALT], Stockholm 60 years old and IMPROVE study [Sixty] and the Stockholm Diabetes Prevention Program [SDPP]), Norway (Oslo Health Study [HUBRO]), Copenhagen, Denmark (Diet, Cancer and Health study [DCH]), the Netherlands (European Prospective Investigation into Cancer and Nutrition [EPIC] comprising the Monitoring Project on Risk Factors and Chronic Diseases in the Netherlands [EPIC-MORGEN], and EPIC-PROSPECT), Austria (Vorarlberg Health Monitoring and Prevention Programme [VHM\&PP]), Italy (EPIC-Turin, Italian Studies of Respiratory Disorders in Childhood and Environment [SIDRIA]-Rome). The data of the four cohorts in the Stockholm area and the two cohorts in the Netherlands, respectively, were pooled. Therefore, 7 study estimates contributed to the metaanalysis (Table 1, for cohort-specific details see (Nagel et al., 2018). 


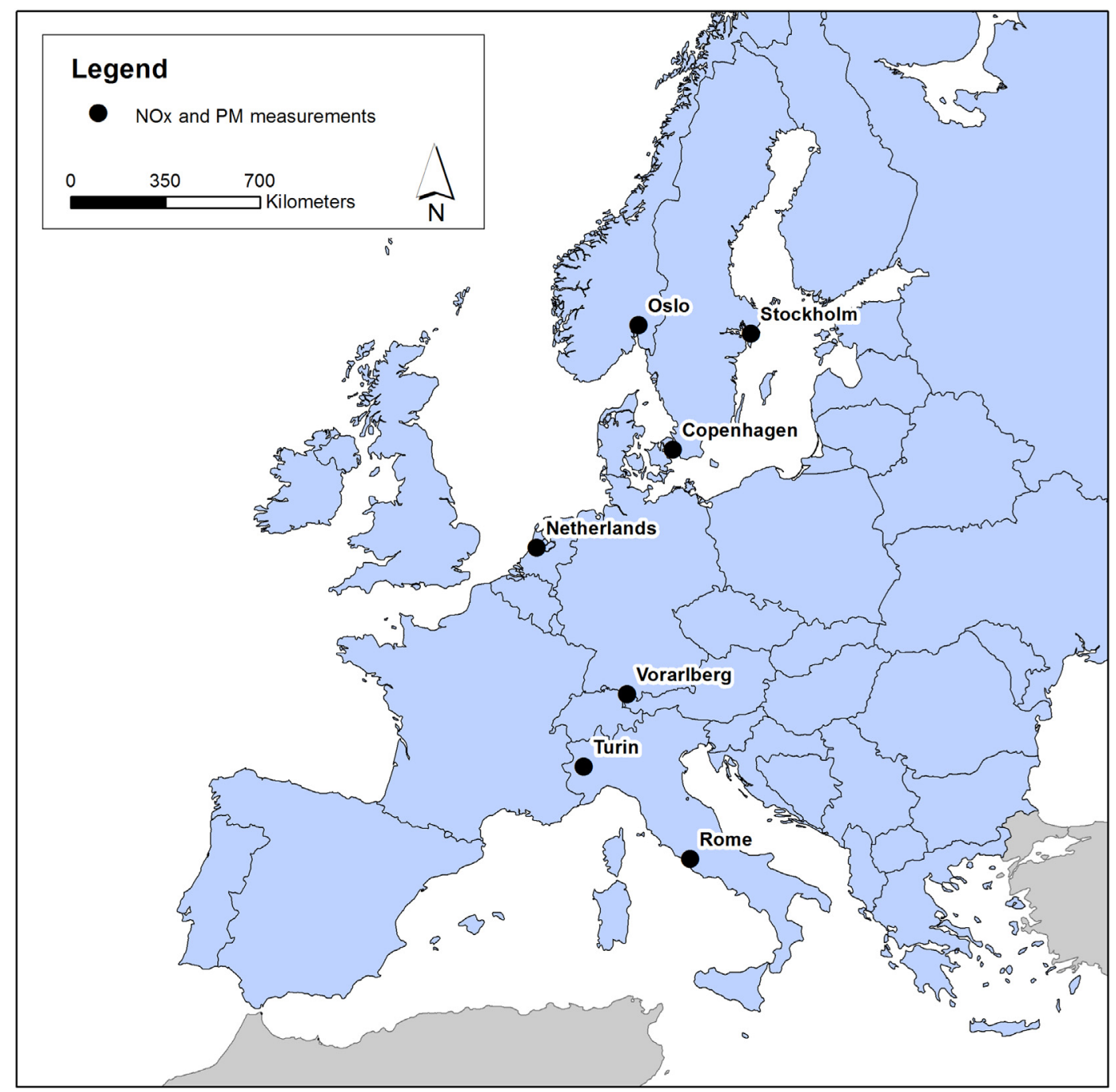

Fig. 1. Location of participating cohorts: Oslo: HUBRO; Stockholm: CEANS (comprising SNAC-K, SALT, Sixty and SDPP); Copenhagen: DCH; Netherlands: EPIC Netherlands; Vorarlberg: VHM\&PP; Turin: EPIC Turin; Rome: SIDRIA; For acronyms of cohorts see Methods section.

Table 1

Participants, gastric and UADT cancer cases and mean $\mathrm{PM}_{2.5}$ concentrations in each cohort.

\begin{tabular}{|c|c|c|c|c|c|c|c|c|c|}
\hline & \multirow[t]{2}{*}{$\begin{array}{l}\text { Total } \\
\text { participants }\end{array}$} & \multirow[t]{2}{*}{ Baseline period } & \multirow{2}{*}{$\begin{array}{l}\text { Mean } \\
\text { follow-up } \\
\text { time }\end{array}$} & \multirow[t]{2}{*}{$\begin{array}{l}\text { Age at baseline } \\
\text { (years) }\end{array}$} & \multicolumn{2}{|c|}{ Incident cases } & \multirow{2}{*}{$\begin{array}{l}\text { Exposure } \\
\mathrm{PM}_{2.5} \\
\left(\mu \mathrm{g} / \mathrm{m}^{3}\right)\end{array}$} & \multicolumn{2}{|c|}{$\begin{array}{l}\text { Persons with stable residence (at least } \\
10 \text { years at baseline address) }\end{array}$} \\
\hline & & & & & $\begin{array}{l}\text { Gastric } \\
\text { cancer }\end{array}$ & $\begin{array}{l}\text { UADT } \\
\text { cancer }\end{array}$ & & Proportion & $\begin{array}{l}\text { Proportion among } \\
\text { cases }\end{array}$ \\
\hline HUBRO, Oslo, Norway & 17,958 & $2000-2001$ & 8.5 & $\begin{array}{l}47.9 \\
(15.0)\end{array}$ & $\begin{array}{l}21 \\
(0.12 \%)\end{array}$ & $\begin{array}{l}23 \\
(0.13 \%)\end{array}$ & $\begin{array}{l}8.9 \\
(1.3)\end{array}$ & 0.39 & 0.67 \\
\hline $\begin{array}{l}\text { CEANS, Stockholm, } \\
\text { Sweden }\end{array}$ & 18,842 & 1992-2004 & 10.4 & $\begin{array}{l}56.2 \\
(11.5)\end{array}$ & $\begin{array}{l}30 \\
(0.16 \%)\end{array}$ & $\begin{array}{l}57 \\
(0.30 \%)\end{array}$ & $\begin{array}{l}7.1 \\
(1.3)\end{array}$ & 0.63 & 0.77 \\
\hline EPIC-Netherlands & 30,134 & 1993-1997 & 11.8 & $\begin{array}{l}50.4 \\
(11.3)\end{array}$ & $\begin{array}{l}41 \\
(0.14 \%)\end{array}$ & $\begin{array}{l}69 \\
(0.23 \%)\end{array}$ & $\begin{array}{l}16.8 \\
(0.6)\end{array}$ & n.d. & n.d. \\
\hline $\begin{array}{l}\text { VHM\&PP, Vorarlberg, } \\
\text { Austria }\end{array}$ & 104,713 & 1985-2005 & 18.1 & $\begin{array}{l}42.9 \\
(14.9)\end{array}$ & $\begin{array}{l}375 \\
(0.36 \%)\end{array}$ & $\begin{array}{l}311 \\
(0.30 \%)\end{array}$ & $\begin{array}{l}13.6 \\
(1.2)\end{array}$ & 0.58 & 0.74 \\
\hline EPIC-Turin, Italy & 7946 & 1993-1998 & 14.1 & $\begin{array}{l}50.4 \\
(7.5)\end{array}$ & $\begin{array}{l}26 \\
(0.33 \%)\end{array}$ & NA & $\begin{array}{l}30.1 \\
(1.7)\end{array}$ & n.d. & n.d. \\
\hline SIDRIA-Rome, Italy & 9775 & 1999 & 11.2 & $\begin{array}{l}44.2 \\
(6.0)\end{array}$ & $\begin{array}{l}20 \\
(0.20 \%)\end{array}$ & $\begin{array}{l}20 \\
(0.20 \%)\end{array}$ & $\begin{array}{l}19.4 \\
(1.8)\end{array}$ & 0.72 & 0.70 \\
\hline
\end{tabular}

Data are $\mathrm{n}$, mean (SD), and $\mathrm{n}(\%) . \mathrm{PM}_{2.5}=$ particulate matter with diameter $<2.5 \mu \mathrm{m}$. NA = not available. HUBRO=Oslo Health Study. CEANS $=$ Swedish National Study on Aging and Care in Kungsholmen (SNAC-K) + Stockholm Screening Across the Lifespan Twin study and TwinGene (SALT) + Stockholm 60 years old and IMPROVE study (Sixty) + Stockholm Diabetes Prevention Program (SDPP). DCH = Diet, Cancer and Health study. EPIC = European Prospective Investigation into Cancer and Nutrition. VHM\&PP = Vorarlberg Health Monitoring and Prevention Programme. SIDRIA = Italian Studies of Respiratory Disorders in Childhood and Environment. n.d. = no data available. 

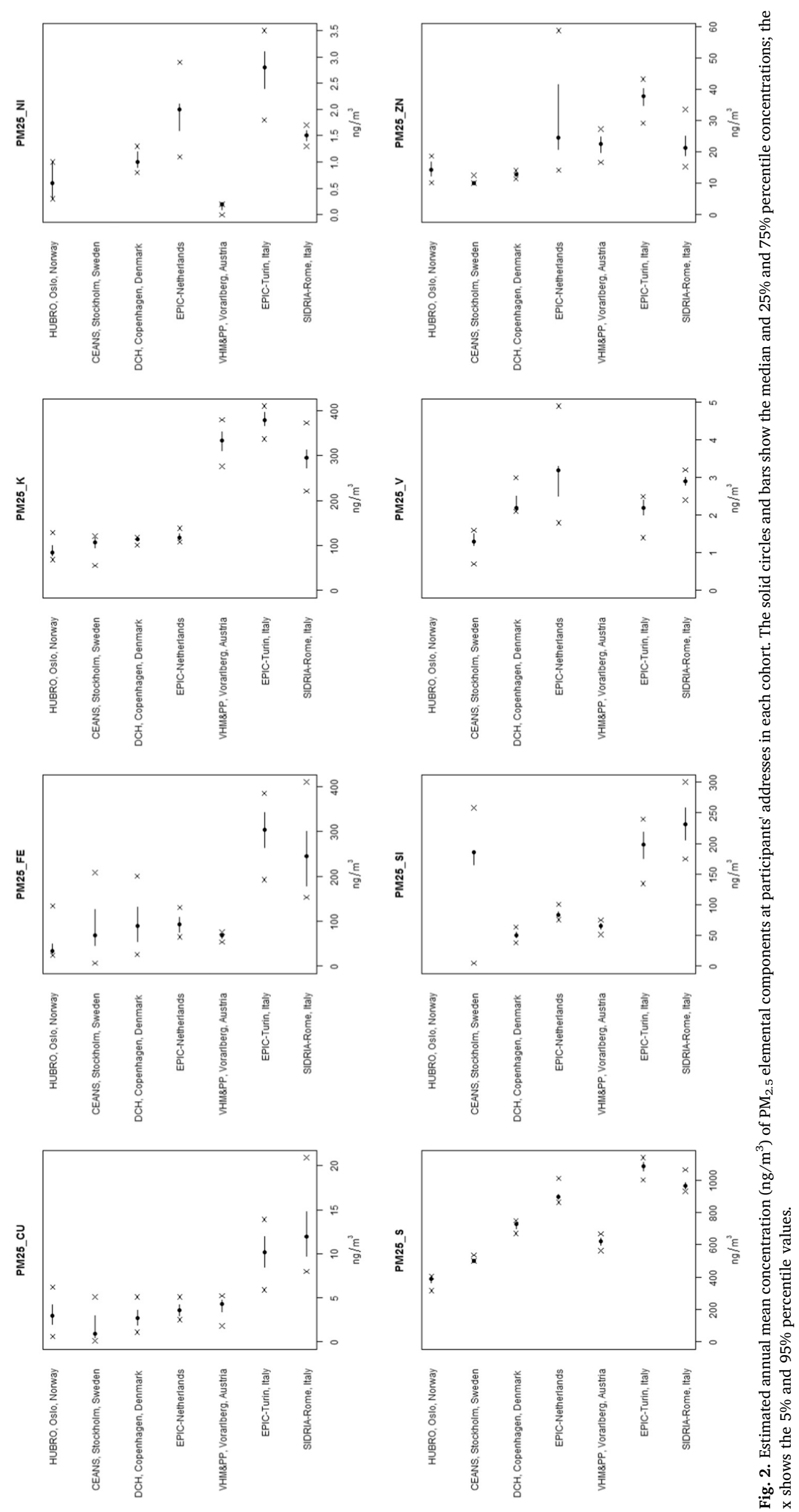
Recruitment of the cohorts occurred largely in the 1990s. The cohort studies and the use of their data in ESCAPE were approved by the local ethical and data protection authorities.

\subsection{Outcome definition}

Follow-up was based on linkage to national or local cancer registries, with exception of SIDRIA Rome for which hospital discharge and mortality register data were used. The main outcomes were all cancers of the stomach and of the UADT, respectively. Carcinomas were identified using the International Statistical Classification of Diseases and Related Health Problems, 9th and 10th revision [ICD9 and ICD10]: for gastric cancer C16 [ICD10] and 151 [ICD9], and for UADT cancers: C01-06 and 141-145 (oral cavity), C09, C10 (oropharynx), C12, C13 (hypo-pharynx) and 146 (pharynx), C14, C32 and 161 (larynx), C15 and 150 (esophagus). Lymphomas/myelomas/leukemias were excluded according to the International Classification of Diseases for Oncology (ICDO-3) morphology codes: 9590-9989. We only included primary cancers and only malignant tumors with the fifth digit of the ICDO morphology code being " 3 ".

\subsection{Exposure assessment}

Exposures at the residential baseline address of the participants were determined according to a standardized procedure by assigning air pollution exposure estimates derived from land use regression (LUR) models specifically developed for the respective areas (de Hoogh et al., 2013). If a subject moved the new address was not taken into account except for exclusion of these subjects in a sensitivity analyses (see below). A detailed description of the 3-step procedure is found elsewhere. First, dedicated measurement campaigns (three two-week periods over one year) were carried out at 20 locations in each study area for a one-year period between October 2008 and May 2011. Results from the three measurements per site were averaged to a mean annual concentration, adjusting for temporal trends using data from a background monitoring site with continuous data.

Second, we collected information about potential predictor variables relating to nearby traffic intensity, population/household density and land use from Geographic Information Systems (GIS), and evaluated these to explain spatial variation of measured annual average concentrations using regression modelling (Beelen et al., 2013; Eeftens et al., 2012). These LUR models were used to estimate the exposure at the baseline address of each cohort member.

To determine the chemical elements contained in the respective PM fractions, PM filters were sent to Cooper Environmental Services (Portland, OR, USA) to analyse elemental composition using X-Ray Fluorescence (XRF). As indicators mainly of non-tailpipe traffic emissions such as brake and tyre wear, $\mathrm{Cu}, \mathrm{Fe}$ and zinc ( $\mathrm{Zn})$ were selected; sulphur (S) mainly for long-range transport; nickel (Ni) and vanadium (V) for mixed oil-burning and industry; silicon ( $\mathrm{Si}$ ) for crustal material and potassium (K) for biomass burning (de Hoogh et al., 2013; Viana et al., 2008). However, each element can have multiple sources. The LUR model results for all study areas have been shown previously (de Hoogh et al., 2013). Land use regression models for $\mathrm{Cu}, \mathrm{Fe}$, and $\mathrm{Zn}$ in both fractions $\left(\mathrm{PM}_{10}\right.$ and $\left.\mathrm{PM}_{2.5}\right)$ had average cross-validation explained variance $\left(r^{2}\right)$ between $52 \%$ and $84 \%$ with a large variability between areas (Raaschou-Nielsen et al., 2016). Models for the other elements performed moderately with average cross-validation $\mathrm{r}^{2}$ generally between $\sim 50 \%$ and $\sim 60 \%$. For $\mathrm{PM}_{2.5} \mathrm{~S}$ the average cross-validation $\mathrm{r}^{2}$ was $32 \%$ with a range from 2 to $67 \%$, consistent with the relatively low spatial variation of PM_S concentrations within the cohort areas. LURmodels could not be developed for $\mathrm{K}$ in $\mathrm{PM}_{10}$ (HUBRO), $\mathrm{Ni}$ in $\mathrm{PM}_{10}$ (HUBRO), $\mathrm{Ni}$ in $\mathrm{PM}_{2.5}$ (CEANS), $\mathrm{V}$ in $\mathrm{PM}_{2.5}$ (HUBRO, VHM\&PP) and $\mathrm{Si}$ in $\mathrm{PM}_{2.5}$ (HUBRO).

\subsection{Statistical analyses}

Cohort-specific analyses were carried out using a common protocol and a centrally developed Stata analysis script (Nagel et al., 2018). In the cases where data of multiple cohorts were pooled (the Swedish and the Dutch cohorts, respectively) the analyses were performed stratifying the Cox Model for a cohort indicator variable.

Cox proportional hazard-regression with age as the underlying timeaxis was carried out. The hazard ratio was modeled as an exponential function of continuous exposure. Censoring was applied at the time of death, a diagnosis of any other cancer (except non-melanoma skin cancer) or end of follow-up, whichever came first. Model checks included a test for deviation from proportional hazard assumption and testing the linearity assumption in the relation between each exposure and the log hazard of the outcome by replacing the linear term with a natural cubic spline with two inner knots placed at the 33rd and 66th percentiles. The model fits of the linear and the spline models were compared using a likelihood-ratio test (Chi-square test with $2 \mathrm{df}$ ).

Confounder sets were determined a priori with increasing levels of adjustment, following the procedures of previous ESCAPE studies (Nagel et al., 2018). Model 1 was adjusted for age (time scale), calendar year of enrolment and sex. Model 2 was additionally adjusted for baseline information on smoking status, smoking intensity, smoking duration, occupational exposure, employment status and educational level. Model 3 (the main model) was in addition adjusted for area-level (residential neighborhood or similar) socio-economic status (SES). The availability of these variables varied slightly between cohorts (Nagel et al., 2018). Only complete case analyses were performed. In the few cases where one variable was missing entirely, the cohort was nevertheless analysed using the available confounders. In sensitivity analyses we included additional potential confounders (alcohol consumption, environmental tobacco smoke (ETS), intake of fruit, intake of meat and marital status), restricted the analysis to participants with stable residence during follow-up or for at least 10 years, and included an indicator for urban/rural environment to the main model.

All cohort-specific analyses were done in Stata versions 10 to 14 (StataCorp, College Station, TX).

The results obtained from the cohort-specific analyses were combined with random effects meta-analysis (DerSimonian and Laird, 1986). Heterogeneity between cohorts was tested by the $\chi^{2}$ test from Cochran's Q statistic and quantified with the $\mathrm{I}^{2}$ (Higgins and Thompson, 2002). Stata version 14 (StataCorp) was used for meta-analyses.

\section{Results}

The cohorts contributed together data on 227,044 individuals with an average follow-up time of 14.9 years. 633 incident cases of gastric cancer and 763 of UADT cancer occurred. DCH and VHM\&PP contributed with most of the cases (Table 1). Mean age at baseline in the cohorts ranged from 43 years (VHM\&PP) to 57 years (DCH). The details of each cohort including participants characteristics and availability of variables have been reported previously (Nagel et al., 2018).

There was a wide range of annual mean concentrations of PM elements concentrations within and between study cohorts. Generally, the Nordic countries showed the lowest and the Southern countries the highest levels of PM (Table 1) and similarly for most of the elements, less consistent for $\mathrm{Ni}, \mathrm{V}$ and $\mathrm{Zn}$. Si had relatively high values in Sweden, $\mathrm{S}$ in the Netherlands, and Austria showed high levels of $\mathrm{K}$ in $\mathrm{PM}_{2.5}$ (Fig. 2 and Figure in the online Supplementary Material). For $\mathrm{PM}_{2.5}$ differences in individual exposures were highest in SIDRIA (Rome) for $\mathrm{Cu}, \mathrm{Fe}, \mathrm{K}$, in EPIC Turin and Netherlands for Ni and S, in EPIC-Netherlands for V and $\mathrm{Zn}$ and in CEANS (Stockholm) for Si. The pattern for $\mathrm{PM}_{10}$ was very similar. Correlations of $\mathrm{PM}$ elements with total $\mathrm{PM}_{2.5}$ and $\mathrm{PM}_{10}$ varied between location with median correlation coefficients largely between 0.4 and 0.6 (Raaschou-Nielsen et al., 2016).

In the tests of loglinearity of the dose-response, the p-value of only 4 
were $\leq 0.05$ and only $8 \leq 0.1$. p-values of $<0.05$ were observed for DCH for $\mathrm{PM}_{2.5} \mathrm{~S}$, for EPIC-Turin for $\mathrm{PM}_{10_{-}} \mathrm{K}$ and for VHM\&PP and SIDRIA for $\mathrm{PM}_{10} \mathrm{Si}$ Therefore we took over the results for the linear models for all cohorts and pollutants and consider that this is a valid approximation.

The meta-analysis results from the main model for $\mathrm{PM}_{2.5}$ components showed effect estimates above and below unity. Only the positive association of $\mathrm{PM}_{2.5-} \mathrm{S}$ with gastric cancer incidence was statistically significant with a hazard ratio (HR) of 1.93 (95\%-confidence interval (95\%-CI) 1.13;3.27) for an increase of $200 \mathrm{ng} / \mathrm{m}^{3}$ (Table 2, Fig. 3) with no heterogeneity in cohort results.

The second highest HR was seen for $\mathrm{PM}_{2.5} \mathrm{Zn}$ with 1.63 (95\%-CI $0.88 ; 3.01$ ) for an increase of $10 \mathrm{ng} / \mathrm{m}^{3}$ with heterogeneity between cohorts $\left(\mathrm{I}^{2}=70 \%\right)$ No clear association was found with UADT cancers for any of the $\mathrm{PM}_{2.5}$ elements. Effect estimates from the age-sex adjusted and fully adjusted confounder model did not differ substantially. Also no clear association could be seen between any of the $\mathrm{PM}_{10^{-}}$ components and gastric or UADT cancer incidence (Table in the online Supplementary Material). The association for $\mathrm{PM}_{10} \mathrm{~S}$ with gastric cancer was $0.97(95 \%$-CI $0.67 ; 1.41)$ for an increase of $200 \mathrm{ng} / \mathrm{m}^{3}$, also with no heterogeneity between cohorts. Excluding VHM\&PP which had a weight of $66 \%$ and $71 \%$, in the meta-analysis of $\mathrm{PM}_{2.5} \mathrm{~S}$ and $\mathrm{PM}_{10-} \mathrm{S}$, respectively, yielded a combined HR of 2.75 (95\%-CI 1.10;6.86) and 1,43 (95\%-CI 0,72;2.85), respectively. Excluding the three cohorts (HUBRO, CEANS, EPIC-Netherlands) with a leave-one-out cross-validation (LOOCV) $\mathrm{R}^{2}$ below 0.3 for the LUR-models yielded a HRR of 1,74 (95\%-CI 0,90;3.33) for $\mathrm{PM}_{2.5}$ S.

The results for the association of $\mathrm{PM}_{2.5-} \mathrm{S}$ with gastric cancer were robust to further adjustment for dietary variables and ETS showing no change in the HR, obtained for the respective cohorts in this analysis, of 1.83 (95\%-CI 1.05;3.20), (Fig. 4, additional confounder data available for 6 cohorts). Similarly, adjustment for the rural indicator yielded very similar effect estimates (information available in 5 cohorts). Restriction to the population with a stable residence, which is less subject to misclassification of long-term exposure at the residence, resulted in slightly increased effect estimates, however with wider CIs.
In two-pollutant models, the effect estimated for total $\mathrm{PM}_{2.5}$ changed from $1.36(95 \%$-CI $0.97 ; 1.90)$ to 1.07 (95\%-CI $0.70 ; 1.64)$ when adjusted for $\mathrm{PM}_{2.5-} \mathrm{S}$ and to $1.42(95 \%$-CI $0.68 ; 2.95)$ when adjusted for $\mathrm{PM}_{2.5_{-}} \mathrm{Zn}$. The effect estimated for $\mathrm{PM}_{2.5_{-}} \mathrm{S}$ changed from 1.93 (95\%-CI $1.13 ; 3.27)$ to 1.79 (95\%-CI $0.96 ; 3.37)$ when adjusted for total $\mathrm{PM}_{2.5}$ and the estimate for $\mathrm{PM}_{2.5} \mathrm{Zn}$ was not affected.

\section{Discussion}

This study including cohorts from 6 European countries shows a statistically significant robust association of $\mathrm{PM}_{2.5} \mathrm{~S}$ with gastric cancer incidence. The effect estimate for $\mathrm{PM}_{2.5}$ decreased markedly when adjusted for $\mathrm{PM}_{2.5_{-}} \mathrm{S}$ whereas the estimate for the latter changed little. No further statistically significant association of the elementary compounds with gastric or UADT cancer was observed, including $\mathrm{PM}_{10 \_} \mathrm{S}$.

The identification of $\mathrm{PM}_{2.5} \mathrm{~S}$ as the element most strongly associated with gastric cancer is in agreement with previous analyses within the ESCAPE study on all-cause mortality (Beelen et al., 2015) and lung cancer incidence (Raaschou-Nielsen et al., 2016). In our analysis of gastric cancer, the HR for $\mathrm{PM}_{2.5} \mathrm{~S}$ was larger than for all-cause mortality (HR 1.14) and lung cancer (HR 1.34). In contrast to lung cancer, our estimate for gastric cancer was robust when additionally adjusted for smoking status, smoking intensity, smoking duration, occupational exposure, employment status, educational level, and for area-level (residential neighbourhood or similar) socio-economic status (area SES). However, it is of concern that there was no corresponding association seen for $\mathrm{PM}_{10} \mathrm{~S}$ in contrast to $\mathrm{PM}_{2.5} \mathrm{~S}$. In general, $\mathrm{PM}_{2.5}$ component mass makes up large amount of $\mathrm{PM}_{10}$ component mass and sulphates are mainly present in the $\mathrm{PM}_{2.5}$ fraction (Tsai et al., 2015). Indeed, the actual concentrations measured at the monitoring sites used to develop the LUR models were highly correlated (median within area $r=0.8$ ) (Tsai et al., 2015). At the cohort address, we found a moderate correlation (median $=0.57$ ) between predicted $\mathrm{PM}_{2.5} \mathrm{~S}$ and $\mathrm{PM}_{10 \_} \mathrm{S}$ exposures from the LUR. In the large VHM\&PP cohort, the correlation was identical for measured and modeled concentrations. The lower correlation is likely due to relatively moderate performance of the LUR

Table 2

Results of the random effects meta-analyses of associations between $\mathrm{PM}_{2.5}$ elemental components and the risk for gastric and UADT cancer.

\begin{tabular}{|c|c|c|c|c|c|c|c|c|}
\hline & \multirow{2}{*}{$\begin{array}{l}\text { Fixed increase } \\
\left(\mathrm{ng} / \mathrm{m}^{2}\right)\end{array}$} & \multirow{2}{*}{$\begin{array}{l}\text { Number of } \\
\text { cohorts }\end{array}$} & \multirow[t]{2}{*}{ Number of cases } & \multicolumn{3}{|l|}{$\mathrm{HR}(95 \% \mathrm{CI})$} & \multicolumn{2}{|c|}{ Measures of heterogeneity between cohorts (model 3) } \\
\hline & & & & Model $1^{\mathrm{b}}$ & Model $2^{c}$ & Model $3^{\mathrm{d}}$ & $I^{2}$ & p-Value \\
\hline \multicolumn{9}{|c|}{ Gastric cancer } \\
\hline $\mathrm{PM}_{2.5} \mathrm{Cu}$ & 5 & 7 & 633 & $1.00(0.73-1.38)$ & $1.01(0.70-1.45)$ & $1.05(0.72-1.53)$ & $37.0 \%$ & 0.15 \\
\hline $\mathrm{PM}_{2.5} \mathrm{Fe}$ & 100 & 7 & 633 & $1.04(0.80-1.35)$ & $1.03(0.75-1.42)$ & $1.03(0.75-1.42)$ & $22.5 \%$ & 0.26 \\
\hline $\mathrm{PM}_{2.5} \mathrm{~K}$ & 50 & 7 & 633 & $1.10(0.88-1.37)$ & $1.08(0.87-1.34)$ & $1.21(0.88-1.66)$ & $28.1 \%$ & 0.21 \\
\hline $\mathrm{PM}_{2.5} \mathrm{Ni}$ & 1 & 6 & $603^{1}$ & $0.81(0.40-1.63)$ & $0.77(0.36-1.63)$ & $0.81(0.36-1.83)$ & $60.3 \%$ & 0.03 \\
\hline $\mathrm{PM}_{2.5} \mathrm{~S}$ & 200 & 7 & 633 & $2.07(1.23-3.47)$ & $2.01(1.20-3.38)$ & $1.93(1.13-3.27)$ & $0.0 \%$ & 0.59 \\
\hline $\mathrm{PM}_{2.5} \mathrm{Si}$ & 100 & 6 & $612^{2}$ & $0.97(0.54-1.75)$ & $0.91(0.43-1.91)$ & $0.90(0.41-1.98)$ & $45.2 \%$ & 0.10 \\
\hline $\mathrm{PM}_{2.5} \mathrm{~V}$ & 2 & 5 & $237^{3}$ & $0.95(0.47-1.89)$ & $0.90(0.45-1.80)$ & $0.90(0.45-1.81)$ & $0.0 \%$ & 0.87 \\
\hline $\mathrm{PM}_{2.5} \mathrm{Zn}$ & 10 & 7 & 633 & $1.54(0.80-2.97)$ & $1.54(0.82-2.90)$ & $1.63(0.88-3.01)$ & $70.2 \%$ & $<0.01$ \\
\hline \multicolumn{9}{|c|}{ UADT cancer } \\
\hline $\mathrm{PM}_{2.5} \mathrm{Cu}$ & 5 & 6 & 763 & $1.08(0.83-1.40)$ & $1.03(0.79-1.34)$ & $1.02(0.78-1.33)$ & $0.0 \%$ & 0.64 \\
\hline $\mathrm{PM}_{2.5} \mathrm{Fe}$ & 100 & 6 & 763 & $0.97(0.79-1.18)$ & $0.89(0.73-1.09)$ & $0.90(0.73-1.10)$ & $0.0 \%$ & 0.73 \\
\hline $\mathrm{PM}_{2.5} \mathrm{~K}$ & 50 & 6 & 763 & $1.13(0.78-1.65)$ & $1.12(0.83-1.51)$ & $1.12(0.83-1.51)$ & $22.9 \%$ & 0.26 \\
\hline $\mathrm{PM}_{2.5} \mathrm{Ni}$ & 1 & 5 & $706^{1}$ & $0.97(0.56-1.67)$ & $0.85(0.53-1.35)$ & $0.84(0.51-1.37)$ & $11.6 \%$ & 0.34 \\
\hline $\mathrm{PM}_{2.5} \mathrm{~S}$ & 200 & 6 & 763 & $0.90(0.46-1.75)$ & $0.74(0.28-1.98)$ & $0.75(0.25-2.21)$ & $54.9 \%$ & 0.05 \\
\hline $\mathrm{PM}_{2.5} \mathrm{Si}$ & 100 & 5 & $740^{2}$ & $0.75(0.54-1.04)$ & $0.75(0.54-1.04)$ & $0.76(0.54-1.05)$ & $0.0 \%$ & 0.99 \\
\hline $\mathrm{PM}_{2.5} \mathrm{~V}$ & 2 & 4 & $429^{3}$ & $0.78(0.48-1.28)$ & $0.69(0.42-1.14)$ & $0.68(0.41-1.12)$ & $0.0 \%$ & 0.63 \\
\hline $\mathrm{PM}_{2.5} \mathrm{Zn}$ & 10 & 6 & 763 & $1.09(0.87-1.37)$ & $1.09(0.86-1.38)$ & $1.11(0.82-1.51)$ & $25.6 \%$ & 0.24 \\
\hline
\end{tabular}

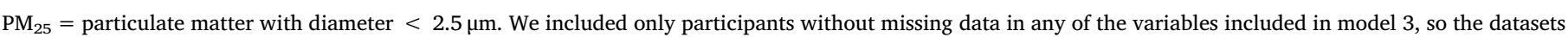
were identical for analyses with all three models. $\mathrm{HR}=$ hazard ratio. $\mathrm{CI}=$ confidence interval. UADT $=$ upper aerodigestive tract.

a Relating to model 3.

b Model 1: age (timescale in Cox model), sex, calendar time.

c Model 2: model 1 + smoking status, smoking intensity, smoking duration, occupational exposure, employment status and educational level.

${ }^{\mathrm{d}}$ Model 3: model 2 + area-level (residential neighbourhood or similar) socio-economic status. 1: without CEANS. 2: without HUBRO. 3: without HUBRO, VHM\& PP. 


\section{$\mathrm{PM}_{2.5} \mathrm{~S}\left(5 \mu \mathrm{g} / \mathrm{m}^{3}\right.$ increase $)$}

$\%$

cohort2
$\operatorname{HR}(95 \% \mathrm{Cl})$

Weight

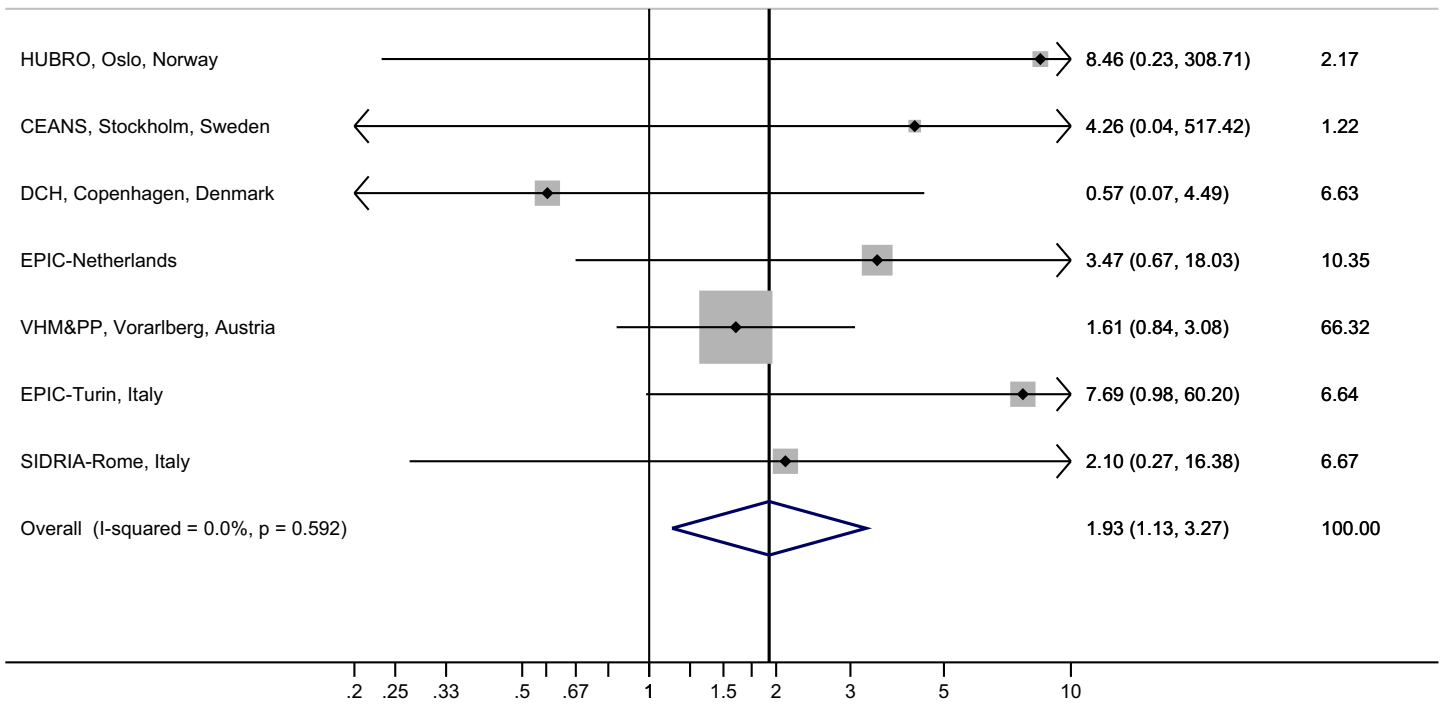

Fig. 3. Risk for gastric cancer associated with $\mathrm{PM}_{2.5} \mathrm{~S}$ in each cohort study.

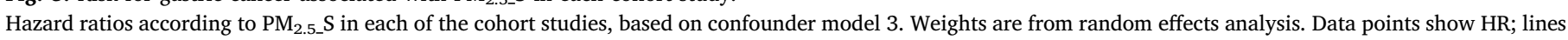

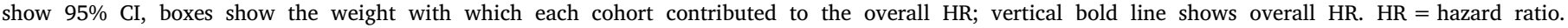
$\mathrm{PM}_{2.5}=$ particulate matter with diameter $<2.5 \mu \mathrm{m}$.

models for S (de Hoogh et al., 2013) and possibly the overrepresentation of traffic locations at the monitoring sites compared to the cohort addresses. Overall, the explained variance of $\mathrm{PM}_{10} \mathrm{~S}$ models was slightly higher than for $\mathrm{PM}_{2.5}$ S LUR models (de Hoogh et al., 2013). The low variability of $S$ within study areas likely has contributed to moderate performance (de Hoogh et al., 2013). In both the mortality and lung cancer studies (Beelen et al., 2015; Raaschou-Nielsen et al., 2016), HRs for $\mathrm{PM}_{10} \mathrm{~S}$, were above unity, but smaller and less consistent than for $\mathrm{PM}_{2.5} \mathrm{~S}$.

For gastric cancer, the null finding for $\mathrm{PM}_{10} \mathrm{~S}$ parallels the nullfinding for total $\mathrm{PM}_{10}$ that we have found in our previous ESCAPE analysis (Nagel et al., 2018).

Overall, our results for $\mathrm{PM}_{2.5} \mathrm{~S}$ were robust as sensitivity analyses did not notably change the effect estimate. Restricting the analyses to persons who lived at least 10 years at their baseline address resulted in slightly increased HRs, which would be expected if the association is true and causal because the degree of non-differential misclassification of exposure is expected to be lower in this sub-population. Excluding the most influential cohort, VHM\&PP with a weight of $66 \%$, increased the HR. Although two-pollutant models should be interpreted with caution (Mostofsky et al., 2012), our finding that the HR in association with $\mathrm{PM}_{2.5-} \mathrm{S}$ is robust when adjusting for $\mathrm{PM}_{2.5}$, which in turn is reduced to virtually no effect, is strengthening our result. Even more so, because in contrast to earlier studies where S and PM were strongly correlated, the moderate correlation in our study (mean of 0.55 ) allows us to be more confident to disentangle effects.

Nevertheless, $\mathrm{PM}_{2.5_{-}} \mathrm{S}$ may also be seen as a marker of a certain pollutant mix. Sources of $S$ are coal, residual oil and motor vehicle fuels. In the NPACT project, the coal combustion source category showed the strongest associations of all investigated sources with longterm effects (mortality in humans and aortic plaque progression in mice) (Lippmann et al., 2013).

Ashely et al. reported a correlation between $\mathrm{SO}_{2}$ exposure and gastric cancer mortality in the UK (Ashley, 1969). This study showed that regions with coal and textile industry had higher gastric cancer mortality. Another study showed that workers exposed to $\mathrm{SO}_{2}$ in the pulp and paper industry had no increased risk of gastric cancer, but mortality from gastric cancer showed a positive dose-response with increasing exposure, however, with very imprecise estimates (Lee et al., 2002).

While an earlier review on toxicological results postulated that there is little evidence that sulphate in ambient concentration is toxicologically relevant (Schlesinger and Cassee, 2003), recent reviews acknowledge that it is unclear which effects are related to sulphates contained in the PM-mixture: the cationic elements $(\mathrm{H}+$, and therefore acidity, and notably (transition) metals) or adsorbed compounds like polyaromatic hydrocarbons (PAH)) may explain the observed epidemiological associations (Cassee et al., 2013; Reiss et al., 2007). A study in Hong Kong (Wong et al., 2012) that investigated the effects of limiting the sulphur content in fuel found that natural mortality was reduced, however the reduction in $\mathrm{SO}_{2}$ was highly correlated with reductions in $\mathrm{V}$ and $\mathrm{Ni}$ and was not statistically significant after adjustment. In our study these metals ( $\mathrm{V}$ and $\mathrm{Ni}$ from residual oil combustion e.g. from industry) were not associated with gastric cancer incidence, although one might argue that the corresponding LURmodels suffered from a lack of sufficiently specific predictors (Beelen et al., 2015).

The possible pathomechanisms of carcinogenicity of sulphate in ambient air for gastric cancer are not clear. Results from experimental research with human bronchial epithelial cells, support the hypothesis that $\mathrm{SO}_{2}$ derivatives could by activation of pro-oncogenes and the inactivation of tumour suppressor genes play a role in the pathogenesis of cancer (Qin and Meng, 2009). It can also be speculated whether the formation of sulphuric acid, which is formed from oxidation from $\mathrm{SO}_{2}$, increases the risk of gastric cancer (Bernatsky et al., 2017). As pointed out above, sulphate may indirectly affect health by e.g. co-occurring 


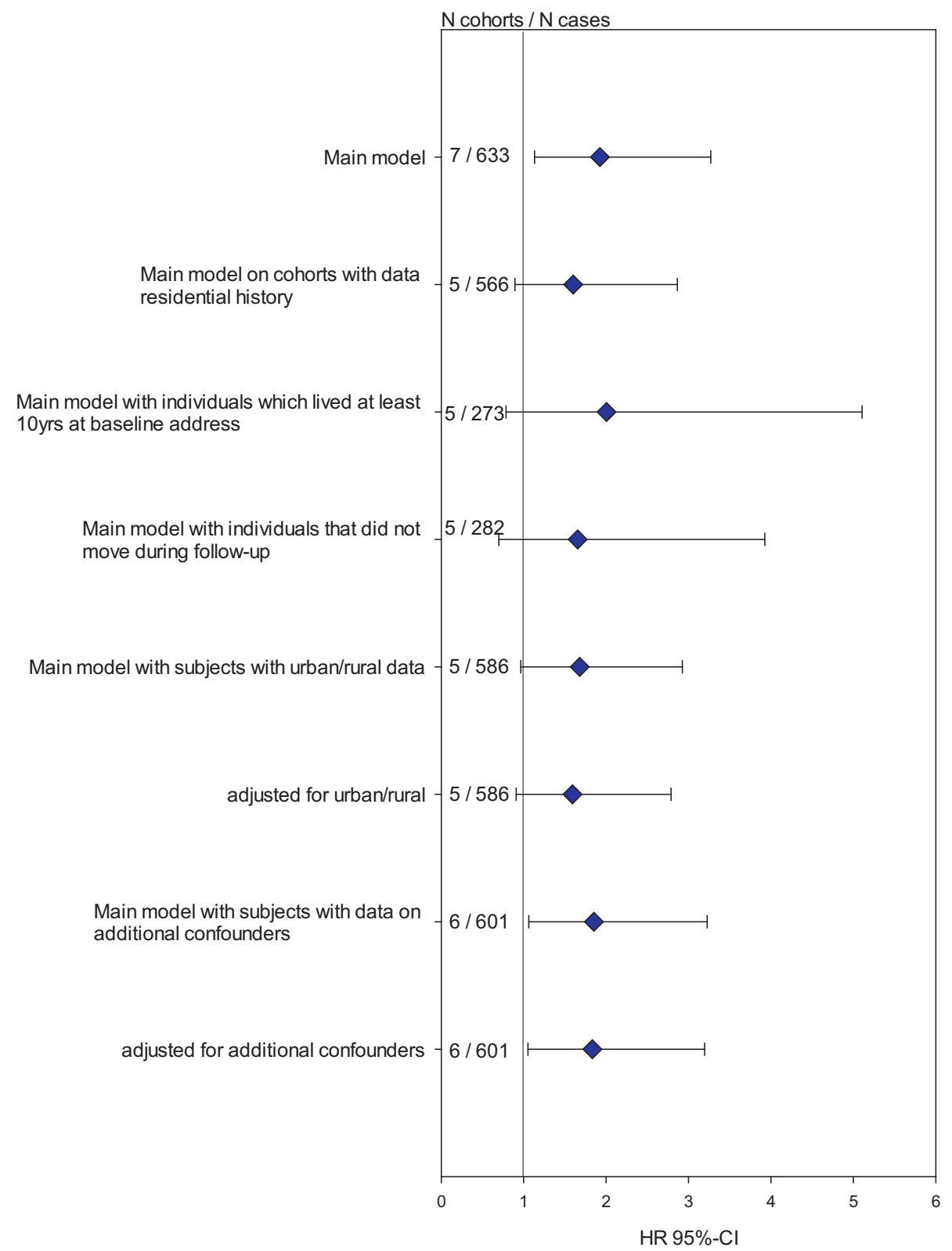

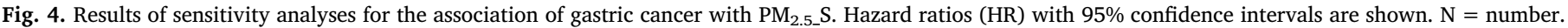
The additional confounders were alcohol consumption, environmental tobacco smoke (ETS), intake of fruit, intake of meat and marital status where available.

transition metals. The bioavailability of these metals may increase (Cassee et al., 2013) and they can lead to the formation of reactive oxygen species (ROS) which in turn may result in oxidative DNA-damage (Møller et al., 2008; Risom et al., 2005).

\subsection{Strengths and limitations}

Our study comprises data from several cohorts from 7 geographical areas, and constitutes the largest data set to date for the analysis of PMelements in relation to gastric cancer. A strength is the common standardized exposure assessment protocol that estimates local concentrations with a small scale resolution. Our analysis was able to take into account important individual confounders, especially smoking. We could also adjust for nutritional variables in 4 of the 7 study-specific effect estimates, but cannot rule out residual confounding. While we cannot exclude the possibility of some misclassification due to the measurement campaigns taking place after recruitment of cohort participants, we were, however, able to take into account information on residential stability, which would tend to decrease the degree of exposure misclassification.

We were not able to take into account the mobility of the individuals, but had to rely on exposure estimates for the residential address at enrolment into the cohorts. Also, the LUR-model approach does involve some degree of misclassification, and especially the performance of the models for PM_S were among the lowest when evaluated by leave-one-out crossvalidation, presumably because of the small measured within-study area contrasts. The average leave-one-out cross-validation (LOOCV) $\mathrm{R}^{2}$ in the present study with data from 7 geographical areas ranged between 7 and $61 \%$ for $\mathrm{PM}_{2.5} \mathrm{~S}$, with the highest values in DCH (61\%) and VHM\&PP (53\%) and the lowest in HUBRO. The sensitivity analyses excluding studies with a (LOOCV) $\mathrm{R}^{2}$ yielded an only mildly attenuated effect estimate with a widened confidence interval, resulting from the exclusion of three of the seven cohorts. It is not clear whether the mild change is related to the LOOCV or other characteristics of the cohorts. We further note that the $\mathrm{I}^{2}$ statistic of the overall analysis is $0 \%$, suggesting that the variability in estimates across cohorts is mostly due to random error. 
Overall, we would expect the misclassification related to low LOOCV $\mathrm{R}^{2}$ to be non-differential and therefore to induce a bias towards the null-effect. Also the relatively poor model fit would not contribute to an erroneously increased effect estimate in the two-pollutant model: indeed, if two pollutants are of similar influence, the pollutant for which the concentrations are more precisely estimated would yield the higher effect estimate. This is unlikely to be the case here, because the model fit for $\mathrm{PM}_{2.5}$ mass was better than for $\mathrm{PM}_{2.5} \mathrm{~S}$ with validation $\mathrm{R}^{2}$ ranging from $42 \%$ to $78 \%$.

In this analysis we tested 32 outcome-exposure combinations, so a chance finding due to multiple testing cannot be fully excluded. Nevertheless, the robustness of the results and the fact that 6 of the 7 cohort estimates were greater than one indicates that the result for $S$ in $\mathrm{PM}_{2.5}$ is probably not due to chance. However, clearly additional specific studies are needed.

Taken together, our results indicate that $\mathrm{S}$ in the $\mathrm{PM}_{2.5}$ fraction, or correlated air pollutants, may contribute to increased risk of cancer of the stomach.

\section{Appendix A. Supplementary data}

Supplementary data to this article can be found online at https:// doi.org/10.1016/j.envint.2018.07.030.

\section{References}

Ashley, D.J., 1969. Environmental factors in the aetiology of gastric cancer. Br. J. Prev. Soc. Med. 23, 187-189.

Beelen, R., Hoek, G., Vienneau, D., et al., 2013. Development of NO2 and NOx land use regression models for estimating air pollution exposure in 36 study areas in Europe The ESCAPE project. Atmos. Environ. 72, 10-23. https://doi.org/10.1016/j. atmosenv.2013.02.037.

Beelen, R., Hoek, G., Raaschou-Nielsen, O., Stafoggia, M., et al., 2015. Natural-cause mortality and long-term exposure to particle components: an analysis of 19 European cohorts within the multi-center ESCAPE project. Environ. Health Perspect. 123, 525-533. https://doi.org/10.1289/ehp.1408095.

Bernatsky, S., Smargiassi, A., Joseph, L., et al., 2017. Industrial air emissions, and proximity to major industrial emitters, are associated with anti-citrullinated protein antibodies. Environ. Res. 157, 60-63. https://doi.org/10.1016/j.envres.2017.04.035.

Cassee, F.R., Héroux, M.-E., Gerlofs-Nijland, M.E., Kelly, F.J., 2013. Particulate matter beyond mass: recent health evidence on the role of fractions, chemical constituents and sources of emission. Inhal. Toxicol. 25, 802-812. https://doi.org/10.3109/ 08958378.2013 .850127$.

de Hoogh, K., Wang, M., Adam, M., et al., 2013. Development of Land Use Regression Models for Particle Composition in Twenty Study Areas in Europe. Environ. Sci. Technol. 47, 5778-5786. https://doi.org/10.1021/es400156t.

DerSimonian, R., Laird, N., 1986. Meta-analysis in clinical trials. Control. Clin. Trials 7, 177-188.

Eeftens, M., Beelen, R., de Hoogh, K., 2012. Development of Land Use Regression models for $\mathrm{PM}_{2.5}, \mathrm{PM}_{2.5}$ Absorbance, $\mathrm{PM}_{10}$ and $\mathrm{PM}_{\text {coarse }}$ in 20 European Study Areas; Results of the ESCAPE Project. Environ. Sci. Technol. 46, 11195-11205. https://doi.org/10. 1021/es301948k.

Hampel, R., Peters, A., Beelen, R., et al., 2015. Long-term effects of elemental composition of particulate matter on inflammatory blood markers in European cohorts. Environ. Int. 82, 76-84. https://doi.org/10.1016/j.envint.2015.05.008.

Higgins, J.P.T., Thompson, S.G., 2002. Quantifying heterogeneity in a meta-analysis. Stat. Med. 21, 1539-1558. https://doi.org/10.1002/sim.1186.

International Agency for Research on Cancer Monograph Working Group, 2015. I. Outdoor air pollution. IARC Press, Lyon, France.

Kelly, F.J., Fussell, J.C., 2012. Size, source and chemical composition as determinants of toxicity attributable to ambient particulate matter. Atmos. Environ. 60, 504-526. https://doi.org/10.1016/j.atmosenv.2012.06.039.

Kelly, F.J., Fussell, J.C., 2015. Air pollution and public health: emerging hazards and improved understanding of risk. Environ. Geochem. Health 37, 631-649. https://doi. org/10.1007/s10653-015-9720-1.

Lee, W.J., Teschke, K., Kauppinen, T., et al., 2002. Mortality from lung cancer in workers exposed to sulfur dioxide in the pulp and paper industry. Environ. Health Perspect. 110, 991-995.

Lippmann, M., Chen, L.-C., Gordon, T., et al., 2013. National particle component toxicity (NPACT) Initiative: integrated epidemiologic and toxicologic studies of the health effects of particulate matter components. In: Research Report 177. Health Effects Institute, Boston, MA.

Møller, P., Folkmann, J.K., Forchhammer, L., et al., 2008. Air pollution, oxidative damage to DNA, and carcinogenesis. Cancer Lett. 266, 84-97. https://doi.org/10.1016/j. canlet.2008.02.030.

Mostofsky, E., Schwartz, J., Coull, B.A., et al., 2012. Modeling the association between particle constituents of air pollution and health outcomes. Am. J. Epidemiol. 176, 317-326. https://doi.org/10.1093/aje/kws018.

Nagel, G., Stafoggia, M., Pedersen, M., et al., 2018. Air pollution and incidence of cancers of the stomach and the upper aerodigestive tract in the European Study of Cohorts for Air Pollution Effects (ESCAPE). Int. J. Cancer. https://doi.org/10.1002/ijc.31564. [Epub ahead of print].

Qin, G., Meng, Z., 2009. Effects of sulfur dioxide derivatives on expression of oncogenes and tumor suppressor genes in human bronchial epithelial cells. Food Chem. Toxicol. 47, 734-744. https://doi.org/10.1016/j.fct.2009.01.005.

Raaschou-Nielsen, O., Andersen, Z.J., Beelen, et al., 2013. Air pollution and lung cancer incidence in 17 European cohorts: prospective analyses from the European Study of Cohorts for Air Pollution Effects (ESCAPE). Lancet Oncol. 14, 813-822. https://doi. org/10.1016/S1470-2045(13)70279-1.

Raaschou-Nielsen, O., Beelen, R., Wang, M., et al., 2016. Particulate matter air pollution components and risk for lung cancer. Environ. Int. 87, 66-73. https://doi.org/10. 1016/j.envint.2015.11.007.

Reiss, R., Anderson, E.L., Cross, C.E., et al., 2007. Evidence of health impacts of sulfateand nitrate-containing particles in ambient air. Inhal. Toxicol. 19, 419-449. https:// doi.org/10.1080/08958370601174941.

Risom, L., Møller, P., Loft, S., 2005. Oxidative stress-induced DNA damage by particulate air pollution. Mutat. Res. Mol. Mech. Mutagen. 592, 119-137. https://doi.org/10. 1016/j.mrfmmm.2005.06.012.

Schlesinger, R.B., Cassee, F., 2003. Atmospheric secondary inorganic particulate matter: the toxicological perspective as a basis for health effects risk assessment. Inhal. Toxicol. 15, 197-235. https://doi.org/10.1080/08958370304503.

Tsai, M.-Y., Hoek, G., Eeftens, M., et al., 2015. Spatial variation of PM elemental composition between and within 20 European study areas - results of the ESCAPE project. Environ. Int. 84, 181-192. https://doi.org/10.1016/j.envint.2015.04.015.

Viana, M., Kuhlbusch, T.A.J., Querol, X., et al., 2008. Source apportionment of particulate matter in Europe: a review of methods and results. J. Aerosol Sci. 39, 827-849. https://doi.org/10.1016/j.jaerosci.2008.05.007.

Wong, C.-M., Rabl, A., Thach, Et Al., 2012. Impact of the 1990 Hong Kong legislation for restriction on sulfur content in fuel. In: Research Report 170. Health Effects Institute, Boston, MA. 